\title{
CASE BASED REASONING UNTUK MENDIAGNOSA PENYAKIT DAN HAMA PADA TANAMAN MANGGA MENGGUNAKAN ALGORITMA SIMILARITAS SORGENFREI
}

\author{
Anton Setiawan ${ }^{1}$, Setyawan Wibisono ${ }^{2}$ \\ 1,2Program Studi Teknik Informatika, Fakultas Teknologi Informasi, Universitas Stikubank Semarang \\ email: ${ }^{1}$ ants.setiawan@gmail.com, ${ }^{2}$ setyawan@edu.unisbank.ac.id
}

\begin{abstract}
Abstrak
Untuk mendapatkan suatu informasi tentang bagaimana mendiagnosa penyakit dan hama pada tanaman mangga secara digital maka dibutuhkan suatu aplikasi dalam bentuk sistem pakar yang dapat mewakili seorang pakar yang ahli di bidangnya untuk memberikan solusi terhadap permasalahan tanaman mangga. Case Based Reasoning untuk mendiagnosa penyakit dan hama tanaman mangga menggunakan algoritma similaritas Sorgenfrei adalah sebuah sistem pakar yang dapat sebagai alat bantu untuk melakukan konsultasi tentang penyakit dan hama tanaman mangga. Untuk mengimplementasikan Case Based Reasoning diperlukan empat tahapan proses yaitu retrieve, reuse, revise, dan retain. Sistem yang telah memberikan hasil dari perhitungan dengan nilai paling tinggi yang akan dijadikan solusi penyakit dan hama tanaman mangga. Pada proses revise, sistem akan meninjau kembali hasil perhitungan penyakit tanaman mangga. Jika hasil tersebut kurang atau sama dengan 20 persen, maka sistem tidak akan memberikan solusi penyakit tanaman mangga, dikarenakan informasi berupa penyakit yang tidak memenuhi syarat akan masuk ke dalam tabel revise yang selanjutnya akan diperbaiki kembali oleh pakar untuk menemukan solusi yang tepat. Setelah proses revise selesai dan sudah ditemukan solusi yang benar-benar tepat barulah pakar mulai menambah aturan dengan memasukan data kasus baru yang sudah ditemukan solusinya proses inilah yang dinamakan dengan proses retain.
\end{abstract}

Kata Kunci: algoritma similaritas Sorgenfrei, Case Based Reasoning, mangga, sistem pakar

\section{PENDAhuluan}

Sistem pakar merupakan aplikasi kecerdasan buatan atau Artifical Intelligence (AI) yang berusaha mengadopsi pengetahuan manusia ke komputer, agar komputer dapat menyelesaikan masalah seperti yang biasa dilakukan oleh para ahli. Salah satu masalah dalam sistem pakar adalah dalam bidang pertanian, di antaranya untuk mendiagnosa penyakit dan hama pada tanaman mangga.

Mangga (Mangifera indica) di Indonesia merupakan komoditas ekspor. Mangga Probolinggo terutama varietas Arumanis sangat populer bahkan sudah dipasarkan sampai ke luar negeri seperti ke Singapura. Namun, tumbuhan tidak selamanya dapat terlepas dari serangan hama dan penyakit. Hama dan penyakit tanaman dapat disebut juga sebagai organisme pengganggu tanaman. Hewan dapat disebut hama karena mereka mengganggu tumbuhan dengan memakannya. Belalang, kumbang, ulat, wereng, tikus, walang sangit merupakan beberapa contoh binatang yang sering menjadi hama tanaman. Terdapat puluhan bahkan ratusan jenis hama dan penyakit yang menyerang tanaman. Berbagai hama dan penyakit pada tanaman mangga yang menyerang dapat ditandai dari gejala-gejala serangan yang timbul. Dengan adanya sistem pakar nanti diharapkan berguna bagi petani untuk mengetahui beberapa jenis hama atau penyakit yang paling umum atau yang paling sering menyerang sehingga dapat meminimalkan kerugian atau kerusakan tanaman mangga.

Untuk memberikan suatu informasi tentang bagaimana mendiagnosa penyakit dan hama pada tanaman mangga, dibutuhkan suatu aplikasi sistem pakar yang dapat mewakili seorang pakar yang ahli di bidangnya untuk memberikan solusi terhadap permasalahan tanaman mangga. Metode Case Based Reasoning ini adalah salah satu metode untuk membangun sistem pakar dengan pengambilan keputusan dari kasus yang baru dengan berdasarkan solusi dari kasus-kasus sebelumnya. 


\section{TINJAUAN PUSTAKA}

Buah durian adalah salah satu buah tropik yang berasal dari Asia Tenggara yang cukup digemari oleh masyarakat. Penyakit pada buah durian sering dijumpai misalnya gala-gala/penggerek buah yang biasanya untuk mengetahui ciri-ciri durian yang terserang hama dan penyakit masih menggunakan diagnosa manual oleh para ahli tanaman secara langsung. Untuk itu diperlukan sistem pakar berbasis web untuk mengidentifikasi jenis hama dan penyakit durian serta penanggulangnya [1].

Pengembangkan sistem pakar yang bergerak di bidang pertanian, yaitu sistem yang dapat diterapkan pada kasus penentuan penyakit pada tanaman melon serta cara penanggulangannya. Penentuan penyakit pada tanaman melon serta cara penanggulangannya sering menjadi permasalahan bagi petani melon. Untuk penentuan penyakit dibutuhkan seorang pakar yaitu seorang ahli dalam bidang pertanian khususnya tanaman melon. Untuk mencari informasi atau bertanya langsung pada ahlinya tentu saja memakan waktu yang tidak sedikit, bahkan ahli pertanian tidak selalu dapat membantu memecahkan permasalahan tersebut setiap waktu. Untuk alasan tersebut, maka perlu dikembangkan suatu sistem pakar untuk mempermudah user dalam menentukan penyakit pada tanaman melon berdasarkan gejala-gejala yang ada. Sistem pakar ini akan dibangun dengan menggunakan metode Case Based Reasoning. Metode ini akan mengambil solusi dari kasus-kasus sebelumnya yang akan digunakan untuk menyelesaikan kasus baru. Sistem ini bertujuan untuk meneliti apakah Case Based Reasoning dapat digunakan untuk menentukan penyakit pada tanaman melon [2].

Hama dan penyakit yang menyerang tanaman mangga meyebabkan petani mangga mengalami kerugian karena tanamanya rusak atau gagal panen. Untuk membantu kerja para penyuluh pertanian dalam mendiagnosa hama dan penyakit yang menyerang mangga apabila pakar dan ahli pertanian belum ada atau tidak ada, maka diperlukan sebuah sistem berbasis komputer yang dapat memberikan informasi hama dan penyakit dan tata cara pengendaliannya. Penelitian ini membangun sebuah sistem pakar berbasis aturan (rule based) dengan menggunakan metode certainty factor untuk mendiagnosa hama dan penyakit. Hasil yang diperoleh yang harus dilakukan, serta nilai certainty factor akan kebenaran dari hama atau penyakit tersebut [3].

Hasil panen padi dari tahun ke tahun mengalami penurunan dikarenakan tanaman padi retan terhadap hama dan penyakit. Maka diperlukan suatu aplikasi sistem pakar yang diharapkan mampu mngatasi masalah tersebut. Aplikasi yang dibangun menggunakan 3 tahapan proses identifikasi penyakit tanaman padi, yaitu tahapan praproses grayscale digunkan untuk ektrasi ciri warna, ektrasi ciri menggunkan local binary pattern dan metode Jensen Shannon Divergence untuk mengklasifikasikan dengan cara menghitung kedekatan vector dari citra sampel dan citra uji. Dalam penlitian ini terdapat 4 jenis penyakit utama yaitu tungro, hawar daun, leafblas dan bercak coklat. Dari hasil pengujian yang dilakukan tingkat akurasi data dalam proses identifikasi penyakit pada padi adalah $86 \%$ [4].

\section{METODE PENELITIAN}

\subsection{Case Based Reasoning (CBR)}

Case Based Reasoning (CBR) adalah salah satu metode untuk membangun sistem dengan pengambilan keputusan untuk memecahkan kasus atau masalah yang baru dengan cara mengingat solusi dari kasus lama/sebelumnya dengan menggunakan informasi dan pengetahuan pada situasi tersebut. Semakin mirip masalah, semakin mirip pula solusinya.

CBR dapat digunakan untuk menyimpan dan menggunakan kembali pengetahuan dari pengalaman sebelumnya. Dalam CBR pengalaman dimodelkan ke dalam bentuk problem dan solusi dan biasa disebut dengan kasus (case). Berdasarkan model deskripsi suatu masalah dan solusi yang berisi hasil penyelesaian masalah. Siklus Case Based Reasoning ditunjukkan pada gambar 1. 


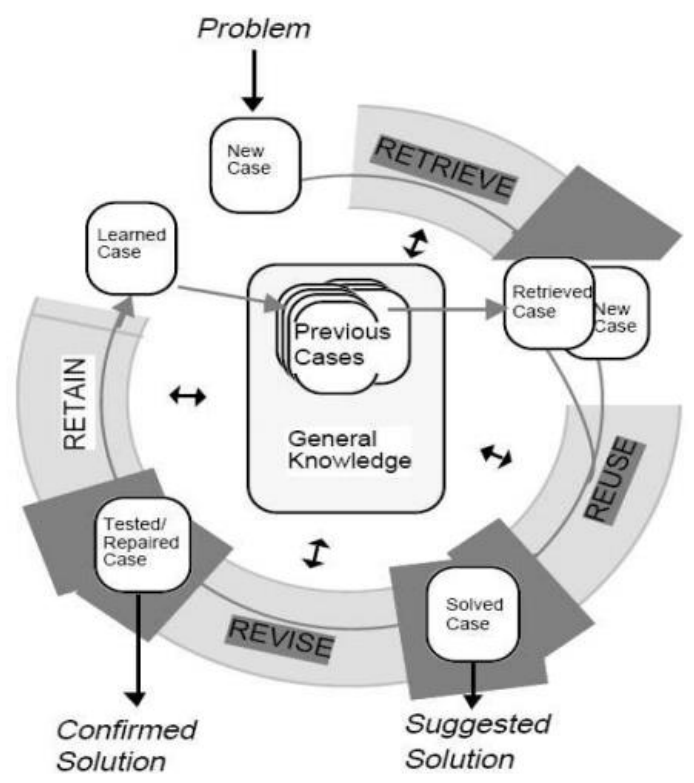

Gambar 1. Siklus CBR [5]

Untuk kasus - kasus yang tersimpan dalam tempat penyimpanan kasus (case based) disebut dengan kasus asal (source case), sedangkan untuk yang baru akan dicari solusinya disebut dengan kasus target (target case). Secara umum, metode ini terdiri dari 4 langkah antara lain:

1. Retrieve (penelusuran)

Proses akan dimulai dengan tahapan mengenali masalah, dan berakhir ketika kasus yang ingin dicari solusinya telah ditemukan serupa dengan kasus yang telah ada. Proses retrieve akan melakukan dua langkah pemrosesan, yaitu pencarian persamaan masalah (similar case) atau pencarian masalah baru (new case) pada database.

2. Reuse (menggunakan kembali)

Masalah/kasus untuk mencoba memecahkan masalah/kasus. Reuse suatu kasus dalam konteks kasus baru terfokus pada dua aspek yaitu perbedaan antara kasus yang ada dengan kasus yang baru, serta bagian mana dari penelusuran kasus yang dapat digunakan pada kasus yang baru.

3. Revise (meninjau kembali/memperbaiki) usulan solusi

Revise terdiri dari dua tugas, yaitu mengevaluasi solusi kasus yang dihasilkan oleh proses reuse. Jika berhasil, maka dilanjutkan dengan proses retain, serta jika tidak maka memperbaiki solusi kasus menggunakan domain spesifik pengetahuan.

4. Retain (menyimpan)

Proses retain akan menggunakan solusi baru sebagai bagian dari kasus baru. Selanjutnya, solusi baru itu akan disimpan ke dalam knowledge-based (basis pengetahuan) kemudian kasus baru diupdate ke dalam basis kasus untuk menyelesaikan permasalahan yang akan datang. Tentunya permasalahan yang akan diselesaikan adalah permasalahan yang memiliki kesamaan. Pada tahap ini terjadi suatu proses penggabungan dari solusi kasus yang baru dan benar ke knowledge yang telah ada.

\subsection{Algoritma K-Nearest Neighbor (K-NN)}

K-Nearest Neighbor adalah sebuah algoritma untuk melakukan klasifikas terhadap objek berdasarkan data pembelajaran yang jaraknya paling dekat dengan objek tersebut. Kasus khusus di mana klasifikasi diprediksikan berdasarkan data pembelajaran yang paling dekat dengan kata lain, $\mathrm{k}$ disebut algoritma Nearest Neighbor [6].

Rumus untuk menghitung nilai K-Nearest Neighbor adalah:

$$
\text { Similirity (problem, case })=\frac{\left(s_{1} * w_{1}\right)+\left(s_{2} * w_{2}\right)+\ldots+\left(s_{n} * w_{n}\right)}{\left(w_{1}\right)+\left(w_{2}\right)+\cdots+\left(w_{n}\right)}
$$

Keterangan: 
$\mathrm{S}=$ similarity (nilai kemiripan) yaitu 1 (sama) dan 0 (beda)

$\mathrm{W}=$ weight (bobot yang diberikan)

Rumus K-Nearest Neighbor diatas digunakan untuk menyempurnakan tingkat nilai kemiripan, dengan metode indexing antara KNN dan Sorgenfrei dapat melakukan perhitungan tingkat kemiripan yang lebih sempurna dari dua buah objek yang diteliti.

\subsection{Algoritma Similaritas Sorgenfrei}

Similaritas merupakan ukuran kedekatan antara satu objek dengan objek lainnya. Kemudian yang dimaksud dengan similaritas Sorgenfrei adalah metode yang digunakan untuk menghitung kemiripan antara jarak dua distribusi probabilitas dengan rumus sebagai berikut:

Keterangan:

$$
\text { Sorgenfrei }=\frac{\mathbf{a}^{2}}{(a+b) \times(a+c)}
$$

$\mathrm{S}=$ Nilai similaritas

$\mathrm{a}=$ Jumlah atribut yang sama antara konsultasi dan data yang tersimpan dalam database

$\mathrm{b}=$ Jumlah atribut yang dimiliki data yang tersimpan dalam database, namun tidak dimiliki data konsultasi

$\mathrm{c}=$ Jumlah atribut yang dimiliki data konsultasi, namun tidak dimiliki data yang tersimpan dalam database

Dari rumus di atas Sorgenfrei merupakan konsep penting dalam teori informasi, karena jumlah informasi-teori lainnya termasuk entropi dan informasi timbal balik dapat diformulasikan sebagai kasus khusus. Sorgenfrei juga memainkan peranan penting dalam menghasilkan besarnya kemiripan termasuk asymptotic tingkat penurunan probabilitas kesalahan dalam pengujian hipotesis masalah biner. Selain itu, perbedaan telah terbukti berguna dalam aplikasi [7].

\subsection{Deskripsi Sistem}

Case Based Reasoning untuk mendiagnosa penyakit dan hama tanaman mangga menggunakan algoritma similaritas Sorgenfrei dapat digunakan untuk melihat informasi penyakit dan hama tanaman mangga. Dalam memulai proses pada aplikasi ini dibedakan menjadi dua yaitu pengguna dan administrator. Untuk pengguna yang belum mempunyai username dan password dapat melakukan registrasi pada from registrasi aplikasi. Baru pengguna dapat melakukan konsultasi dengan memilih gejala yang dialami tanaman mangga.

Untuk mengimplementasikan Case Based Reasoning diperlukan empat tahapan proses yaitu retrieve, reuse, revise, dan retain, sistem yang telah memberikan hasil dari perhitungan dengan nilai paling tinggi yang akan dijadikan solusi penyakit dan hama tanaman mangga. Pada proses revise, sistem akan meninju kembali hasil perhitugan penyakit tanaman mangga. Jika hasil tersebut kurang dari atau sama dengan 20 persen, maka sistem tidak akan memberikan solusi penyakit tanaman mangga. Dikarenakan informasi berupa penyakit yang tidak memenuhi syarat akan masuk ke dalam tabel revise yang selanjutnya akan diperbaiki kembali oleh pakar untuk menemukan solusi yang tepat. Setelah proses revise selesai dan sudah ditemukan solusi yang benar-benar tepat barulah pakar mulai menambah aturan dengan memasukan data kasus baru yang sudah ditemukan solusinya proses inilah yang dinamakan dengan proses retain.

Pengguna dapat memilih gejala yang dialami oleh tanaman mangga, kemudian sistem akan menampilkan data penyakit dan hama tanaman mangga kepada user dengan perintah SQL. Sedangkan admin harus login terlebih dahulu agar dapat untuk memilih menu gejala penyakit, penyakit dan revise. Pada menu gejala, admin dapat melakukan inputan data gejala penyakit baru. Untuk mengedit data yang dipilih dari tabel data yang ditampilkan, setelah pengeditan selesai data-data tersebut akan ditransferkan ke variabel-variabel yang ditentukan dengan format kalimat SQL. Dalam proses hapus mengambil data yang berada di tabel dengan format kalimat SQL delete. Alur kerja user dapat dilihat pada gambar 2 . 


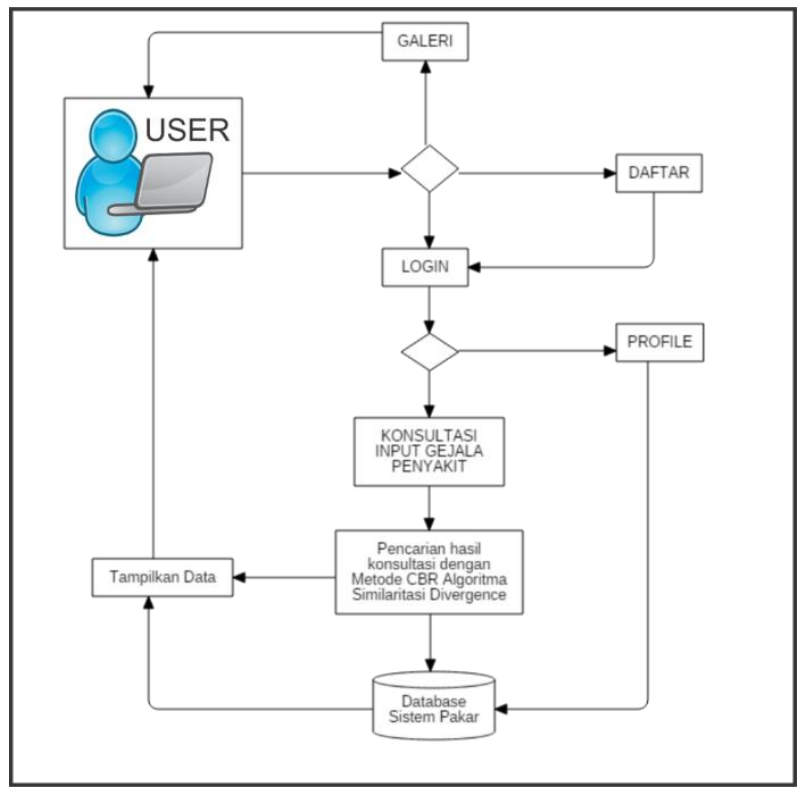

Gambar 2. Blok diagram proses kerja user

Pada menu penyakit, input data, edit data, dan hapus data proses kerjanya sama dengan proses menu gejala penyakit yaitu menambah data penyakit yaitu dengan query input, edit dengan query update, dan hapus dengan query delete. sedangkan alur kerja admin ditunjukkan pada gambar 3.

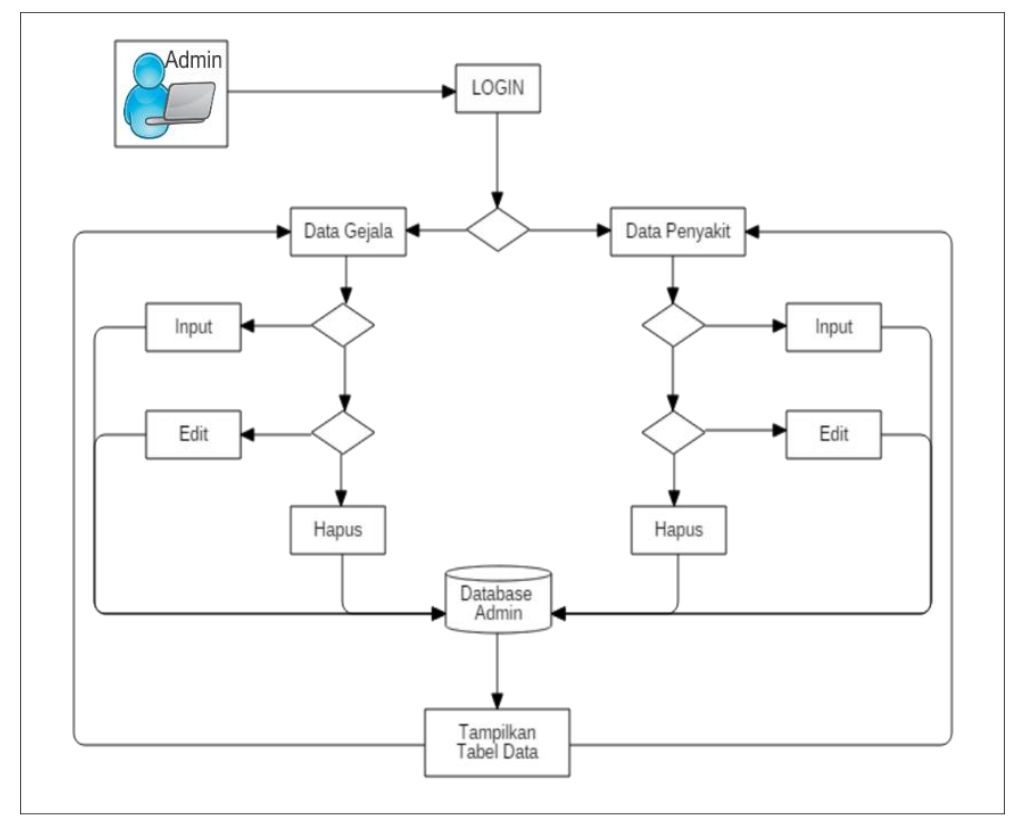

Gambar 3. Blok diagram proses kerja administrator

\subsection{Arsitektur Sistem}

Sistem ini dibagi menjadi 3 lapisan yaitu: lapisan database, lapisan bahasa query dan lapisan aplikasi. Lapisan database merupakan lapisan yang digunakan untuk menyimpan data gejala dan penyakit. Media penyimpanan data dalam aplikasi ini menggunakan AppServ 2.5.9 dengan format data SQL. Lapisan query merupakan lapisan PHP query yang digunakan untuk pemisahan variabel data yang akan diubah ke dalam format SQL sebelum melakukan penyimpanan data. Lapisan aplikasi adalah antarmuka dalam aplikasi yang memudahkan pengguna untuk melakukan interaksi terhadap sistem. 
Pada antarmuka sistem pengguna yang akan melakukan pencarian gejala penyakit dapat menginputkan gejala. Sistem akan menggunakan lapisan query untuk mencari dengan menggunakan algoritma similaritas pada database dan menampilkan hasil similaritas terbesar.

Pada antarmuka admin terdapat form login untuk selanjutnya menampilkan pilihan gejala dan penyakit. Form gejala digunakan untuk melihat data gejala dalam bentuk tabel. Pada tabel gejala penyakit dapat melakukan input, edit, dan hapus data gejala. Form penyakit digunakan untuk melihat data penyakit dalam bentuk tabel. Pada tabel penyakit, admin dapat melakukan input, edit, dan hapus bahan. Untuk mengaplikasikan aplikasi antarmuka menggunakan bahasa pemrograman PHP. Arsitektur sistem diperlihatkan pada gambar 4.

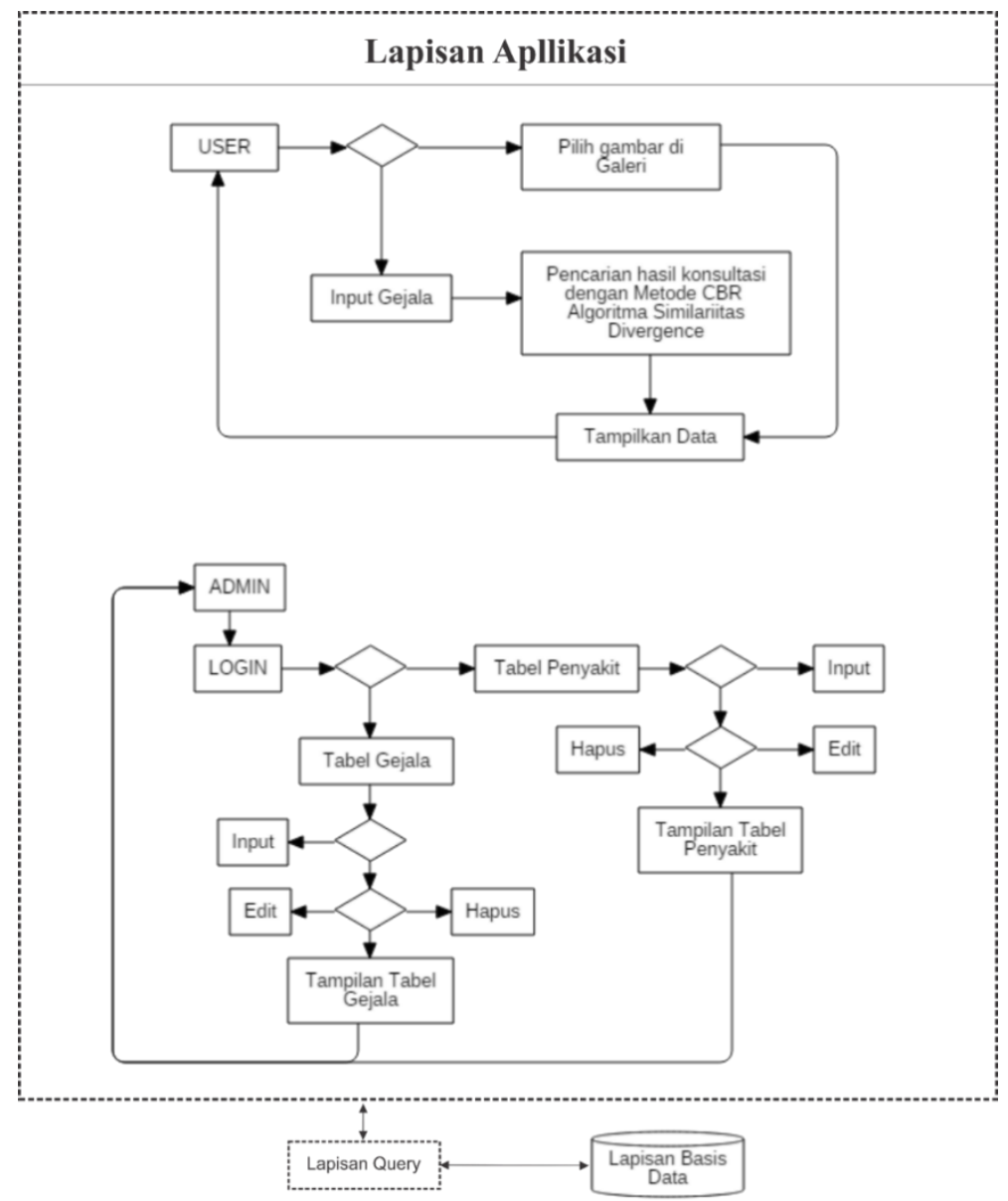

Gambar 4. Arsitektur sistem

\subsection{Analisa Data Penyakit dan Gejala}

Dalam pembuatan sebuah sistem perlu adanya data penunjang seperti data gejala, data penyakit dan gambar. Data tersebut bisa diperoleh dari hasil wawancara, jurnal dan buku agar nantinya dapat dikonversikan ke dalam sistem guna mempermudah proses pencarian solusi. Data penyakit dan data gejala digunakan sebagai pola pencocokan informasi yang dimasukan oleh user dan berbasis pengetahuan seperti terlihat pada tabel 1 .

Tabel 1. Penyakit dan Solusi

\begin{tabular}{|l|l|l|}
\hline Kode & \multicolumn{1}{|c|}{ Penyakit } & \multicolumn{1}{c|}{ Solusi } \\
\hline P001 & Antraknose & $\begin{array}{l}\text { Memotong dan memusnahkan bagian tanaman yang terserang, } \\
\text { Membersihkan dan memusnahkan daun-daun kering, buah } \\
\text { yang gugur di sekitar tanaman. Pada saat tampak gejala awal } \\
\text { dilakukan penyemprotan fungisida DELSENE MX -200, } \\
\text { DEROSAL 500 EC atau ALTO 100 SL. }\end{array}$ \\
\hline P002 & Penyakit & Ranting atau cabang yang terserang dipotong dan dibakar, \\
\hline
\end{tabular}




\begin{tabular}{|c|c|c|}
\hline & Diplodia & $\begin{array}{l}\text { batang yang terserang dikupas kulit luarnya sampai batas } \\
\text { jaringan kayu, kemudian diolesi dengan fungisida BENLATE } \\
\text { seminggu sekali. Apabila gejala awal muncul pada saat buah } \\
\text { masih muda, disemprot dengan fungisida KOCIDE } 10 \text { hari } \\
\text { sekali sebanyak } 3 \text { kali. }\end{array}$ \\
\hline P003 & iloesporium & Fungsida bubur Bordeaux. \\
\hline P004 & $\begin{array}{l}\text { Penyakit } \\
\text { Cendawan } \\
\text { Jelaga }\end{array}$ & $\begin{array}{l}\text { Dengan memberantas serangga yang menghasilkan cairan } \\
\text { manis dengan insektisida atau tepung belerang. }\end{array}$ \\
\hline P005 & Penyakit Kudis & $\begin{array}{l}\text { Fungisida Dithane M-45, Manzate atau Pigone tiga kali } \\
\text { seminggu. Memangkas tangkai bunga yang terserang. }\end{array}$ \\
\hline P006 & $\begin{array}{l}\text { Bercak Karat } \\
\text { Merah }\end{array}$ & $\begin{array}{l}\text { Pemangkasan daun, cabang, ranting, menyemprotkan fungisida } \\
\text { bubuk bordeaux atau sulfat tembaga. }\end{array}$ \\
\hline P007 & $\begin{array}{l}\text { Penyakit Kulit/ } \\
\text { Blendok }\end{array}$ & $\begin{array}{l}\text { Memotong bagian yang sakit, lubang ditutupi dengan kapas } \\
\text { yang telah dicelupkan ke dalam insektisida dan menyemprot } \\
\text { pohon dengan bubur bordeaux. }\end{array}$ \\
\hline P008 & Benalu & $\begin{array}{l}\text { Potong bagian cabang dan ranting yang sudah terjangkiti } \\
\text { benalu hingga benar-benar bersih tidak ada lagi akar benalu } \\
\text { yang menempel. }\end{array}$ \\
\hline P009 & $\begin{array}{l}\text { Wereng } \\
\text { Mangga }\end{array}$ & $\begin{array}{l}\text { Dengan pengasapan, memotong bagian bunga yang terserang, } \\
\text { kemudian dimusnahkan. Menyuntik pohon mangga dengan } \\
\text { insektisida sistemik sebanyak } 10-20 \text { cc per pohon. } \\
\text { Menyemprotkan insektisida APLAUD } 400 \text { F atau } \\
\text { DARMABASH 500. }\end{array}$ \\
\hline $\mathrm{P} 010$ & $\begin{array}{l}\text { Ulat Penggerek } \\
\text { Buah }\end{array}$ & $\begin{array}{l}\text { Membungkus (membrongsong) buah dengan kertas semen. } \\
\text { Menyemprotkan insektisida AGROTHION 50 EC atau } \\
\text { AMCOTHENE } 75 \text { SP pada saat buah muda. Memusnahkan } \\
\text { buah-buah yang gugur. }\end{array}$ \\
\hline P011 & Lala & $\begin{array}{l}\text { Membungkus (membrongsong) buah muda sampai menjadi tua } \\
\text { dengan kertas semen. Memasang umpan metyl eugenol. } \\
\text { Menyemprotkan insektisida DECIS atau TALSTAR } 25 \text { EC } \\
\text { pada saat buah muda. Memusnahkan buah-buah busuk. }\end{array}$ \\
\hline P012 & Bisul Daun & $\begin{array}{l}\text { Penyemprotan buah dan daun dengan Ripcord, Cymbuth atau } \\
\text { Phosdrin tiga kali dalam seminggu. Membakar daun yang } \\
\text { terserang. Menggemburkan tanah untuk mengeluarkan } \\
\text { kepompong dan memperbaiki aerasi. }\end{array}$ \\
\hline P013 & $\begin{array}{l}\text { Thrips } \\
\text { (Scirtothrips } \\
\text { dorsalis) }\end{array}$ & $\begin{array}{l}\text { Tunas muda terserang dipotong lalu dibakar. Tangkap dengan } \\
\text { perangkap warna kuning. Pemangkasan teratur. Penyemprotan } \\
\text { dengan menggunakan produk nasa yang berupa pestona }+ \\
\text { Aero-810 dengan dosis }(5+1 / 3) \text { tutup /tangki semprot, } \\
\text { lakukan penyemprotan di sore hari. }\end{array}$ \\
\hline P014 & Codot/Kalong & $\begin{array}{l}\text { Dengan membiarkan semut kerangkang hidup di sela daun } \\
\text { mangga. Memasang kitiran angin berpeluit dan melindungi } \\
\text { pohon dengan jaring atau di brongsong. }\end{array}$ \\
\hline
\end{tabular}

Tabel gejala adalah tabel yang akan digunakan sebagai basis pengetahuan. Data gejala yang dihimpun adalah data gejala yang nantinya akan dimasukkan dalam konsultasi maupun data gejala suatu penyakit dan hama tanaman mangga yang sudah dicatat dalam basisdata seperti terlihat pada tabel 2. 
Tabel 2. Gejala

\begin{tabular}{|l|l|}
\hline \multicolumn{1}{|c|}{ Kode } & \multicolumn{1}{|c|}{ Gejala } \\
\hline G001 & Bercak hitam kecoklatan/kemerahan pada daun \\
\hline G002 & Bunga menjadi mengering dan berguguran \\
\hline G003 & Bercak hitam pada buah dan berguguran \\
\hline G004 & Kulit batang/ranting pecah-pecah \\
\hline G005 & $\begin{array}{l}\text { Mengelurakan cairan getah berwarana coklat kehitaman pada } \\
\text { batang }\end{array}$ \\
\hline G006 & Kulit batang menglupas dan akhirnya bisa mati \\
\hline G007 & Daun berbintik hitam dan menggulung \\
\hline G008 & Bunga menjadi layu \\
\hline G009 & Buah busuk \\
\hline G010 & Daun berubah menjadi hitam \\
\hline G011 & Bercak kuning yang akan berubah menjadi abu-abu \\
\hline G012 & Mempengaruhi proses pembuahan \\
\hline G013 & Bercak coklat kemerahan pada daun dan bunga \\
\hline G014 & Pohon menjadi susah besar alias pertumbuhannya lambat \\
\hline G015 & Daun mulai berkurang sehingga pohon terlihat gersang \\
\hline G016 & Buah berlubang dan mengeluarkan getah \\
\hline G017 & Kulit buah terdapat titik noda hitam \\
\hline G018 & Buah jatuh/berguguran \\
\hline G019 & Permukaan daun berbintil-bintil menyerupai bisul \\
\hline G020 & Daun Memucat \\
\hline G021 & Daun berguguran \\
\hline G022 & Tunas daun layu \\
\hline G023 & Buah bekas gigitan hama \\
\hline G024 & Mati pucuk \\
\hline
\end{tabular}

\section{HASIL DAN PEMBAHASAN}

Rancangan Case Based Reasoning untuk diagnosa hama dan penyakit tanaman mangga dengan menggunakan algoritma similaritas Sorgenfrei yang telah dibuat akan dilakukan pengujian guna mengetahui kinerja aplikasi, dan berikut hasil pengujiannya.

Perhitungan kasus dengan ID_Kasus: K001 dibandingkan dengan penyakit dengan ID_Penyakit: P001, dengan nama penyakit: Antraknose. Diagnosa pertama dilakukan oleh user dengan memilih gejala tanaman mangga yang berada di dalam tabel seperti tabel 3.

Tabel 3. Contoh gejala dalam konsultasi

\begin{tabular}{|l|}
\hline \multicolumn{1}{|c|}{ Gejala yang dipilih: } \\
\hline Bercak hitam kecoklatan / kemerahan pada daun \\
\hline Kulit batang/ranting pecah - pecah \\
\hline Mati pucuk \\
\hline Bunga menjadi layu \\
\hline Bercak coklat kemerahan pada daun dan bunga \\
\hline Bunga menjadi mengering dan berguguran \\
\hline
\end{tabular}

G 3. Contoh gejala dalam konsultasi

Setelah user memilih gejala, sistem akan melakukan proses pencarian kemiripan gejala yang dipilih dengan gejala pada tabel penyakit. Proses ini dilakukan dengan metode Case Based Reasoning 
dengan algoritma Sorgenfrei. Untuk nilai bobot tiap parameter gejala hanya memilih 1, karena tiap gejala memiliki nilai bobot yang sama. Berikut proses perhitungan pada sistem.

\begin{tabular}{|c|c|}
\hline $\begin{array}{l}\text { ID_Kasus: K001 } \\
\text { Gejala: } \\
\text { - } \text { Bercak hitam kecoklatan / } \\
\text { kemerahan pada daun } \\
\text { - } \text { Kulit batang/ranting pecah - } \\
\text { pecah } \\
\text { - Mati pucuk } \\
\text { - } \text { Bunga menjadi layu } \\
\text { - } \text { Bercak coklat kemerahan pada } \\
\text { daun dan bunga Air } \\
\text { - } \quad \text { Bunga menjadi mengering dan } \\
\text { berguguran }\end{array}$ & $\begin{array}{l}\text { ID_Penyakit: P001 } \\
\text { Nama Resep: Antraknose } \\
\text { Gejala: } \\
\text { - Bercak hitam kecoklatan / } \\
\text { kemerahan pada daun Asam jawa } \\
\text { - Bunga menjadi mengering dan } \\
\text { berguguran } \\
\text { - Bercak hitam pada buah dan } \\
\text { berguguran } \\
\text { - Mati pucuk }\end{array}$ \\
\hline
\end{tabular}

Gambar 6. Ilustrasi pencocokan antara gejala pada data konsultasi dan data penyakit

Dalam tahapan ini akan dilakukan pencocokan antara gejala yang dimasukkan sebagai kasus baru yang dikonsultasikan dengan gejala yang berada dalam sebuah penyakit yang telah tersimpan dalam database. Dari proses pencocokan ini akan terdapat tiga hal penting yang menjadi dasar perhitungan nilai similaritas, yaitu:

1. Gejala yang sama-sama dimiliki oleh konsultasi dan penyakit yang telah tersimpan dalam database, yang dalam algoritma similaritas dinotasikan dengan simbol 'a'.

2. Gejala yang dimiliki oleh penyakit yang telah tersimpan dalam database, namun tidak terdapat dalam konsultasi, yang dalam algoritma similaritas dinotasikan dengan simbol 'b'.

3. Gejala yang dimiliki oleh konsultasi, namun tidak terdapat dalam penyakit yang telah tersimpan dalam database, yang dalam algoritma similaritas dinotasikan dengan simbol 'c'.

Berikut ini adalah contoh proses perhitungan nilai similaritas menggunakan algoritma Sorgenfrei berdasarkan contoh konsultasi K001:

- ID_Penyakit: P001

- Nama penyakit: Antraknose

- Proses penghitungan nilai similaritas dengan pembobotan menggunakan algoritma Sorgenfrei, dengan terlebih dahulu mencari:

$\mathrm{a}=3$

$\mathrm{b}=1$

$\mathrm{c}=3$

- Maka nilai kemiripan dengan menggunakan algoritma Sorgenfrei dihitung sebagai berikut:

$$
\begin{aligned}
\mathrm{S}_{\text {Sorgenfrei }} & =\frac{\mathrm{a}^{2}}{(a+b) \times(a+c)} \\
\mathrm{S}_{\text {Sorgenfrei }} & =\frac{3^{2}}{(3+1) \times(3+3)} \\
\mathrm{S}_{\text {Sorgenfrei }} & =\frac{9}{4 * 6} \\
\mathrm{~S}_{\text {Sorgenfrei }} & =\frac{9}{24} \\
\mathrm{~S}_{\text {Sorgenfrei }} & =0.375
\end{aligned}
$$

Dari hasil perhitungan algoritma similaritas Sorgenfrei diketahui bahwa pada kasus dengan ID_Kasus K001 jika dibandingkan penyakit P001 akan diperoleh nilai kemiripan sebesar 0,375, yang dapat diartikan bahwa kasus K001 mempunyai kemiripan yang relatif rendah, karena nilai kemiripan mempunyai rentang 0 sampai dengan 1 . Nilai 0 adalah nilai kemiripan yang menyatakan tidak ada kemiripan sama sekali, sedangkan nilai kemiripan 1 adalah nilai kemiripan yang menyatakan bahwa kasus baru sama persis dengan resep masakan yang ada dalam basisdata.

\section{KESIMPULAN}


Case Based Reasoning untuk mendiagnosa penyakit dan hama pada tanaman mangga menggunakan algoritam similaritas Sorgenfrei dapat digunakan untuk mencari data penyakit yang mengindentifikasi suatu gejala yang di masukan user. Semua gejala yang ada dalam database mempunyai nilai bobot 1 (satu), karena semua penyakit memungkinkan memiliki gejala yang sama dengan yang lainnya. Sistem tidak akan memberikan solusi hama dan penyakit apabila hasil perhitungan similaritas sama dengan atau kurang dari 20 persen. Kemudian sistem akan menampung kedalam tabel revise untuk dicari solusi yang tepat. Proses revise dilakukan oleh admin untuk dilakukan input sebagai data hama penyakit mangga yang baru.

\section{DAFTAR PUSTAKA}

[1] Mundhorie, 2015, Sistem Pakar untuk Mengidentifikasi Hama dan Penyakit Durian Menggunakan Metode Cased Based Reasoning (CBR), Skripsi, Universitas Stikubank Semarang

[2] Setiyanto, Y, 2013, Case Based Reasoning untuk Diagnosa Penyakit pada Tanaman Melon, Skripsi, Universitas Kristen Duta Wacana Yogyakarta

[3] Bumi, K.H.C., Azhari, S., 2013, Sistem Pakar Diagnosa Hama dan Penyakit pada Tanaman Mangga, Skripsi, Program Studi Ilmu Komputer, Universitas Gadjah Mada Yogyakarta

[4] Dengen, N., 2015, Identifikasi Penyakit Tanaman Padi Menggunakan Jensen Shannon Divergence Berbasis Android, Skripsi, Jurusan S-1 Teknik Informatika, Universitas Halu Oleo, Kendari

[5] Aamodt, A., Plaza, E., 1994, Case Based Reasoning: Foundation Issues Methodological Variation, and System Approaches, AI Communication Vol 7, No 1, March 1994, Pp39-59.

[6] Cover, T., Hart, P., 1967, Nearest Neighbor Pattern Classification, IEEE Transactions on Information Theory, Vol. 13, Ed. 1.

[7] Choi, S. S., Cha, S. H., \& Tappert, C. C. (2010). A Survey of Binary Similarity and Distance Measures, Journal of Systemics, Cybernetics and Informatics, 8 (1), 43-48. 